\title{
Correction to: From hostile worlds to multiple spheres: towards a normative pragmatics of justice for the Googlization of health
}

\section{$\operatorname{Tamar}_{\text {Sharon }}{ }^{1}(\mathbb{0}$}

Published online: 12 May 2021

(c) Springer Nature B.V. 2021

\section{Correction to: Medicine, Health Care and Philosophy} https://doi.org/10.1007/s11019-021-10006-7

In the original publication of this article, the acknowledgement section has been missed to update and the same has been published in this correction.

Acknowledgements I would like to thank Barbara Prainsack for commenting on earlier versions of this manuscript, and Klaus Hoeyer, Andrew Hoffman, Marjolein Lanzing, Lotje Siffels and Tsjalling Swierstra for inspiring discussions that have contributed to this paper.
Publisher's Note Springer Nature remains neutral with regard to jurisdictional claims in published maps and institutional affiliations.

The original article can be found online at https://doi.org/10.1007/ s11019-021-10006-7.

Tamar Sharon

t.sharon@ftr.ru.nl

1 Faculty of Philosophy, Theology and Religious Studies, Radboud University, PO Box 9103, 6500 HD Nijmegen, The Netherlands 